\title{
Conditions for the effective functioning of the system of internalization of economic damage from emissions in the territory
}

\author{
Vladimir Kurdyukov ${ }^{1, *}$ and Sergey Kanurny ${ }^{1}$ \\ ${ }^{1}$ Don State Technical University, sq. Gagarina, 1, Rostov-on-Don, 344003, Russia
}

\begin{abstract}
The results of the study are derived from a framework for estimating and recovering damage from emissions, the assimilation potential and sustainable development goals taken into account as well. The identified conditions for the establishment of an effective system for internalizing economic damage from emissions in the territory are limited to ensuring the fairness and consistency of the decisions taken, formation of incentives for continuous improvement of the situation and achievement of the goals of sustainable development in the territories. The main conditions are to reduce the limitations of traditional methods and to overcome uncertainty in the analysis of data. The development of assimilation potential should generate income for its owner (the source of income is the polluter). If payments for cap-and-trade payments are insufficient, the state must subsidize the activity. Since the estimation of the cost of cap-and-overs is done in some part in isolation, it is possible to identify the economic feasibility of its operation within the framework of the model. Due to importance and complexity, one of the main elements and conditions of an effective system of internalization of externalities in the territory is the solution of the problems of road transport.
\end{abstract}

\section{Introduction}

Transport air pollutant emissions are decreasing in many regions (Trends in air pollution emissions from transport are shown in figure 1). Within large cities, vehicle emissions often account for the majority of total emissions [1]. The planning, construction and operation of transport infrastructure have various adverse environmental impacts [2]. The consideration of externalities of the economic system in the territory as a whole implies better forecasting of the speed of development of various transport modes and the soundness of the investment required for the development of transport systems in countries and regions. These include the internalization of negative externalities and possible steps to take account of positive externalities associated with the provision of transport services [3]. The required policy incentives are linked to additional investment, additional transaction costs, break-even sales of green products and the cost factor, which includes the efficiency

\footnotetext{
* Corresponding author: kurdvn@mail.ru
} 
and effectiveness of using green technologies to save energy and reduce both emissions and business risk [4]. The internalization of externalities through an adjustment tax or a reduced value-added tax removes the price disadvantage of green products such as biomass electricity, making them the preferred choice over cheap traditional products such as coal [5]. However, studies have shown that the degree of internalization of the external costs of specific pollutants does not necessarily imply a reduction in the emissions of these pollutants, as other factors and country characteristics also play an important role [6].

120

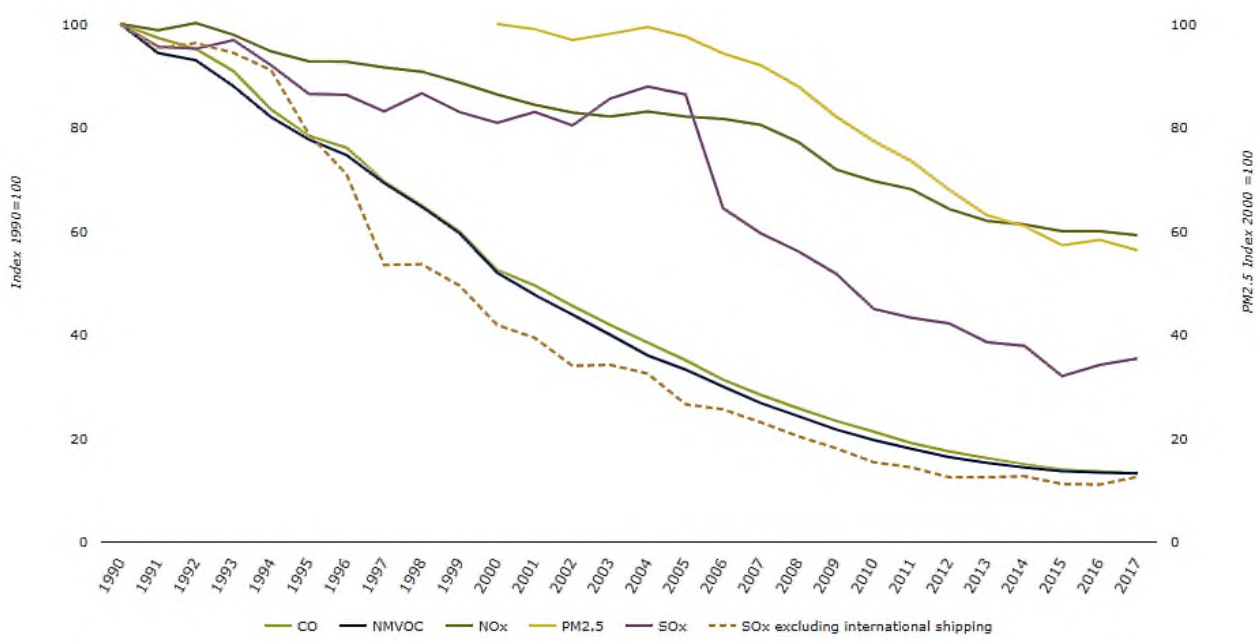

120

Fig. 1. Trends in emission of air pollutants from transport, Source: https://www.eea.europa.eu/dataand-maps/indicators/transport-emissions-of-air-pollutants-8/transport-emissions-of-air-pollutants-8

Simulations of the internalization of external costs of major global environmental problems using an optimal model of economic growth show, for example, that in the near future global warming would be 10 to 40 per cent of all external costs in the 21 st century. The remaining costs will relate to land use and land-use changes. Internalization of external costs would reduce economic growth by about 5 per cent, while forest conservation would increase by 40 per cent and fossil fuel consumption would decrease by 15 per cent. Sustainability estimates imply that the prerequisite for sustainable development is satisfied for the world and for developed countries during the 21 st century, but is not satisfied until the second half of this century for developing countries [7].

It turns out that the ecological efficiency of energy policy can be assessed by two indicators: the reduction of the cost of damage in relation to the reduction of pollutant emissions and the reduction of the number of polluted days per year. Studies in Tehran showed that the most effective mitigation scenario would lead to a $35 \%$ reduction in the average PM2.5 concentrations in 2030 and a $20 \%$ reduction in the number of polluted days. These results show how the linear relationship of the damage estimate to emission levels can distort the environmental impact assessment. This is due to neglecting the effects of source distribution and the geographical conditions of the environment [8]. Another study shows that full internalization of damage in each sector requires higher tax rates in some sectors and lower rates in others [9]. It should also be noted that the stringency of environmental policies has a strong impact on $\mathrm{CO} 2$, NOx and SOx emissions, while environmental policies have little impact on both PM2.5 emissions and their impacts [10]. 
The author [11] argues that in the real world, where external factors predominate, their internalization or neutralization in the traditional way cannot lead to sustainability. Sustainability can only be ensured if internalization takes a very specific form that will lead to the irrevocable preservation of the environmental rights of future generations in purely biological categories.

From a governance perspective, standards are essential for the inclusion of nongovernmental stakeholders, including industry and environmental organizations, in the setting of policy benchmarks [12]. However, all types of tools of the emission reduction policy face challenges in their development and implementation: understanding the impact of the selected tools, implementing enhanced levels of stringency, making commitments at an appropriate scale and ensuring the stability of the policy itself. Knowledge of the marginal cost of abatement can help to assess the economic impact of various farm strategies aimed at reducing emissions, as well as to introduce incentive mechanisms by government decision-makers [13].

Internalization of externalities is an important element of territorial sustainability. Completeness and stricter internalization do not necessarily reduce emissions and losses. Problems with pollution modelling and damage assessment distort the effectiveness of certain tools [14]. Standards are a basic element of environmental management in the territory. At the same time, all types of policy tools for reducing emissions face different challenges in development and implementation. Therefore, the analysis of conditions for effective functioning of the system of internalization of damage from emissions in the territory is a relevant scientific task.

\section{Methods}

The methodological basis for the study is a synthesis of the following categories and perceptions [15-17]:

The environmental focus of the territory is the maximum permissible load on the ecosystem (mass of emissions of pollutants, which will eliminate the formation of a concentration of pollutants in the air that is dangerous for humans and the natural environment). It allows dividing emissions into limits and exceedances for the ecosystem.

Assimilation potential is the resource of ecosystem elements to neutralize and process harmful substances without changing basic properties.

Economic damage to an ecosystem is the cost of avoiding negative effects from pollution through ecosystem elements that have assimilation potential [18].

The synthesis of the presented categories implies clarification and development of the perception of the relationship between the following concepts. Externalities and economic damage in the system of internalization of emission damage will characterize the cost of emissions for all those responsible, taking into account the characteristics of a particular ecosystem. Internalization of externalities, internalization of damage from emissions, and compensation of damage are similar in content, but different in scope, the key element of which is the allocation of responsibility (can form a solution without implementation). At the same time, the cost of emissions has to be determined for the allocation of liability.

In the view of the categories presented, the system of internalization should include three components related to the determination of the cost of pollutant emissions to internalize the economic damage from environmental pollution in the territory.

1. Emissions of pollutants are less than or equal to the maximum permissible load on the ecosystem. To ensure the economic cost-effectiveness on increasing the assimilation potential, the cost of emissions must be «tied» to the economic damage to the ecosystem. In 
this case, the cost of limit emissions would take into account the damage to the ecosystem and the profit of the owner of the assimilation potential.

2. Emissions of pollutants are higher than the maximum permissible load on the ecosystem but lower than the assimilation potential. Estimates of the cost of this component of emissions, in addition to those included in the first case, include damage to public health, man-made and natural facilities.

3. Pollutant emissions are greater than the assimilation potential of the ecosystem. The cost of this part of the excess emissions cannot include the profit of the owner of the assimilation potential, as the beneficial effect does not extend to this part of the emissions.

The internalization of economic damage from actual emissions of pollutants is the sum of emission values of the three components described.

Thus, a synthesis of the maximum permissible load on the ecosystem, assimilation potential and economic damage to the ecosystem was used as the main components in achieving the objective of the study.

\section{Results}

Effective environmental management involves the establishment of a management system and mechanisms to reduce damage caused by pollutants in the territory. The basic element of the decision-making system is the information support and the analysis of raw data. The completeness, comparability and adequacy of the indicators characterizing the state of the system to a large extent ensure the attainability of management goals. In other words, shortcomings of the approaches to situation analysis and assessment of the state of the facility create methodological limitations both for determining the most effective management decisions within the framework of the budget deficit, and in general, the limits of the effectiveness of environmental protection measures. Given the significant impact of vehicle emissions on the air environment of territories, their assessment and internalization is an urgent and complex task.

The environmental management practices of western countries are connected with better technical facilities and the accumulation of a substantial empirical database. Economic management practices are replacing outdated technologies and keeping the territory's vehicle fleet up to date. However, the monitoring system in place also fails to reduce uncertainty and can only provide an indirect assessment of the effectiveness of management decisions. Managing the environment through trend assessment limits the ability to select the most effective solutions.

Decision-making is implemented within the framework of existing or emerging systems and involves several steps [15]. An analysis of the elements of environmental protection management has revealed shortcomings in the transition to ecologically sustainable development. Based on the previously identified shortcomings [15] and taking into account the research methodology and the objectives of sustainable development, the following conditions for the effective functioning of the system of internalization of economic damage from emissions in the territory can be identified:

1. Choosing a monetization method. The system of internalization of damage from emissions may include different tools. The effectiveness of certain tools can vary significantly for different territories, industries, types of pollution sources and depends on many factors. The choice of an environmental policy tool should take into account the selection criteria, specificities of the legislative framework, enforceability of compliance with the legislation, technological development, characteristics of the institutional environment, the standard of living of the population, etc. 
2. Consistency forms factors and conditions for increasing the model of internalization of the emissions damage efficiency. Different strategies for internalization of externalities and monetization may be appropriate for different territories, industries, sources of pollution. Their lack of coherence in the system of internalization of damage from emissions in a territory may undermine its effectiveness.

3. An integrated model for assessing damage from emissions to form a territorial internalization model. For stationary and mobile sources of pollution, exposure environments, the identification and assessment of consequences can present various difficulties. In this sense, research should aim at improving assessment approaches in the context of the sustainable development concept and the simplification of management decision-making (this can be measured by the total costs and benefits, including minimizing the transaction costs of policy formation and implementation).

4. Assessment of alternatives. Advantage in the cumulative costs and benefits of an ongoing project to internalize externalities in the territory over alternative and other environmental projects.

5. The equality of marginal costs and marginal benefits, used as a criterion for environmental decision-making, should be taken into account in the assessment of emissions damage when forming a model of internalization of externalities in the territory. Use of costs on ecosystem elements with assimilation potential to prevent adverse effects from emissions as equivalent of damage will allow to determine the limit values of the alternative costs to prevent damage from emissions for a specific ecosystem.

6. The specific fee for limit emission (within the maximum permissible load on the ecosystem) should not exceed the fee for the over-limit emissions (exceeding the maximum permissible load on the ecosystem). Since the estimation of the cost of cap-and-overs is done in some part in isolation, it is possible to identify the economic feasibility of its operation within the framework of the model. The development of assimilation potential should generate income for its owner (the source of income is the polluter). This income per unit of emissions should not exceed the specific estimate of the negative consequences of over-limit emissions. In addition, if payments for cap-and-trade payments are insufficient, the state must subsidize the activity, the proposed emission recovery model is not economically feasible at this stage and includes the implementation of additional environmental protection measures, as well as ensuring conditions for a reasonable increase in pollution charges.

7. Stimulating effect of applied tools. Failure to comply with this condition prevents the transition to sustainable development in the territory and generates an accumulation of various problems. The absence or decrease of the stimulating effect may be due to various market mechanism problems (market failures, monopolization, etc.), shortcomings and limitations in assessing negative effects of emissions and the system of allocation of responsibility, systems of situation control and integrity of conduct, economic and technical conditions.

8. Internalization of damage from vehicle emissions in the territory. The peculiarities of environmental pollution by road transport, the manifestations of the negative consequences thereof and the significance in the total mass of emissions in many territories make it possible to speak of the road transport complex as one of the most difficult objects for the internalization of externalities [16]. In various situations, the conditions for both effective functioning and the introduction of a system for internalizing the economic damage caused by emissions from road transport may be compatible with the objectives of a system for accounting emissions and allocation of responsibility, social and economic impact, complexity of administration and control. 
Deficiencies, incomplete internalization of damage from emissions affect the economic performance and losses, budget and the efficiency of the territory's economy as a whole. The establishment of an effective system for the internalization of damage from emissions in the territory is an important element of the strategy for the transition to sustainable development of territories. At the same time, the analysis and consideration of ecosystemspecific factors and the conditions for the effective functioning of the system for internalizing economic damage from emissions in the territory can help to increase sustainability in all spheres of life.

\section{Conclusion}

Depending on the objective, it is necessary to choose an internalization tool and an approach to assessing the damage from pollutant emissions [17]. The establishment of an effective system of internalization of externalities requires consideration of a number of conditions. The significance of conditions and their correlation with selection criteria for environmental policy instruments depends to a large extent on the priority objective pursued in the territory. Compliance with the goals of sustainable development in the territory implies, among other things, an equitable distribution of benefits and resources. In this context, equity criteria must be taken into account in order to build an effective system of internalization of externalities in the territory. The establishment, development and adaptation of equity criteria is an important element of future scientific research in this subject area.

A synthesis of categories such as maximum permissible load on the ecosystem, assimilation potential and economic damage to the ecosystem was used as the main component for improving the information support system for environmental and economic decision-making.

In connection with the reasonable significance of choosing an approach for assessing economic damage from emissions, an economic damage estimation method that takes into account the assimilation potential of the ecosystem is used. According to the calculated data, the total damage exceeds by more than 100 times the damage estimate, according to the recommended method in the Russian Federation. This difference suggests that the current recommendations for determining economic damage from emissions do not cover the cost of pollutants disposal with assimilation potential (not to mention the damage to public health).

Assessing the fairness of a positive rate of return for the owner of the assimilation potential in compensating for damage from limit emissions in the territory, it should be noted that compensation for damage from limit emissions (at the level of the maximum permissible load on the ecosystem) is carried out on the basis of the proposed approach for assessing the costs of ecosystem elements that have assimilation potential, and the rate of return can be determined either legislatively or, preferably, by market way. In compensating for damage from over-limit emissions, the necessary cost of ecosystem elements to prevent damage to public health, the costs of eliminating negative consequences of environmental pollution and an analytically grounded share of compensation for economic damage from emissions by the perpetrator should be taken into account. In both cases, a separate estimate of the relative value of the emission mass (limit and over limit for the territory) emerges and, from the economic point of view, the cost of the pollutant mass limit should not exceed the limit value.

The reported study was funded by RFBR according to the research project № 19-010-00904. 


\section{References}

1. Y. Li, Q. Du, X. Lu, J. Wu, X. Han, Relationship between the development and $\mathrm{CO} 2$ emissions of transport sector in China. Transport and Environment, 74, 1-14 (2019) https://doi.org/10.1016/j.trd.2019.07.011

2. E. Broniewicz, K. Ogrodnik, Multi-criteria analysis of transport infrastructure projects. Transportation Research Part D: Transport and Environment, 83, 102351 (2020) doi.org/10.1016/j.trd.2020.102351

3. A. Stetjuha, Manifestation and record of the externalities in the transport services implementation. Procedia engineering, 178, 452-460 (2017) doi.org/10.1016/j.proeng.2017.01.088

4. H. Ding, M. He, C. Deng, Lifecycle approach to assessing environmental friendly product project with internalizing environmental externality. Journal of Cleaner Production, 66, 128-138 (2014) doi.org/10.1016/j.jclepro.2013.10.018

5. T. Lan T. Nguyena, B. Laratteb, B. Guillaumeb, A. Huab, Quantifying environmental externalities with a view to internalizing them in the price of products, using different monetization models. Resources, Conservation and Recycling, 109, 13-23 (2016) doi.org/10.1016/j.resconrec.2016.01.018

6. D. Štreimikienè, Review of internalization of externalities and dynamics of atmospheric emissions in energy sector of Baltic States. Renewable and Sustainable Energy Reviews, 70, 1131-1141 (2017) doi.org/10.1016/j.rser.2016.12.017

7. T. Kosugia, K. Tokimatsub, A. Kurosawab, N. Itsuboc, H. Yagitad, M. Sakagamie, Internalization of the external costs of global environmental damage in an integrated assessment model. Energy Policy, 37, 2664-2678 (2009) doi.org/10.1016/j.enpol.2009.02.039

8. F. Taksibi, H. Khajehpour, Y. Saboohi, On the environmental effectiveness analysis of energy policies: A case study of air pollution in the megacity of Tehran. Science of The Total Environment, 705, 135824 (2020) doi.org/10.1016/j.scitotenv.2019.135824

9. P. K. Wesseh, Jr. aB. Linab, Optimal emission taxes for full internalization of environmental externalities. Journal of Cleaner Production, 137, 871-877 (2016) doi.org/10.1016/j.jclepro.2016.07.141

10. K. Wanga, M. Yana, Y. Wanga, C.-P. Changb, The impact of environmental policy stringency on air quality. Atmospheric Environment, 231, 117522 (2020) doi.org/10.1016/j.atmosenv.2020.117522

11. K. Bithas, Sustainability and externalities: Is the internalization of externalities a sufficient condition for sustainability? Ecological Economics, 70(10), 1703-1706 (2011) doi.org/10.1016/j.ecolecon.2011.05.014

12. S. Goulden, M. Negev, S. Reicher, T. Berman, Implications of standards in setting environmental policy. Environmental Science \& Policy, 98, 39-46 (2019) doi.org/10.1016/j.envsci.2019.05.002

13. L. Cecchini, S. Venanzi, A. Pierri, Massimo Chiorri Environmental efficiency analysis and estimation of $\mathrm{CO} 2$ abatement costs in dairy cattle farms in Umbria (Italy): A SBMDEA model with undesirable output. Journal of Cleaner Production, 197, Part 1, 895907 (2018) doi.org/10.1016/j.jclepro.2018.06.165 
14. V. Kurdyukov, I. Avlasenko, L. Avlasenko, S. Kanurny, Assessment of environmental performance in recreational areas with the consideration of assimilation potential. E3S Web of Conferences, 175, 14003 (2020) doi.org/10.1051/e3sconf/202017514003

15. L. Badalyan, V. Kurdyukov, A. Ovcharenko, K. Gazgireev, Target program formation model to reduce the negative impacts of the transportation sector in the mountainous territory, Sustainable Development of Mountain Territories, 11, 2(40), 249-258 (2019) doi:10.21177 / 1998-4502-2019-112-249-258

16. L. Badalyan, V. Kurdyukov, A. Ovcharenko, Y. Gorshkova, Analysis of standards and methodology for assessing impact of emissions on the atmospheric air quality prevailing in Russian Federation, Sustainable development of mountain territories, 10, 2(36), 307-314 (2018) doi:10.21177/1998-4502-2018-10-2-307-314

17. V. Kurdyukov, L. Badalyan, I. Avlasenko, L. Avlasenko, S. Kanurny, Internalization tool for external effects from emissions of pollutants by motor vehicles. IOP Conf. Series: Earth and Environmental Science, 403 (2019) doi:10.1088/1755$1315 / 403 / 1 / 012080$

18. V. Kurdyukov, Revisited characteristics of Russian economy transition to sustainability. Vestnik of Don State Technical University, V. 11, 6(57), 964-965 (2011) 